\title{
Improving Grain Yield of Indigenous Rice in Tidal Floodplain of Southern Bangladesh: Effect of Seedling Age and Transplanting Method
}

\author{
Abdul Hamid1*, Md. Jafar Ullah'1,2, Md. Moynul Haque3, Md. Faruque H. Mollah', \\ Md. Moksedur Rahman ${ }^{4}$ \\ ${ }^{1}$ Agrarian Research Foundation, Shekhertek, Mohammadpur, Dhaka, Bangladesh \\ ${ }^{2}$ Agronomy Department, Sher-e-Bangla Agricultural University, Dhaka, Bangladesh \\ ${ }^{3}$ Agronomy Department, Bangabandhu Sheikh Mujibur Rahman Agricultural University, Gazipur, \\ Bangladesh \\ ${ }^{4}$ Coastal Ecosystem Unit, Agrarian Research Foundation, Barisal, Bangladesh \\ Email: "hamid.kgf@gmail.com
}

Received 14 November 2015; accepted 25 December 2015; published 29 December 2015

Copyright (C) 2015 by authors and Scientific Research Publishing Inc.

This work is licensed under the Creative Commons Attribution International License (CC BY).

http://creativecommons.org/licenses/by/4.0/

(c) (i) Open Access

\begin{abstract}
Rice production in the tidal floodplain of southern Bangladesh is constrained by uncontrolled water. In absence of high yielding varieties suitable for tidal floodplain, farmers grow low yielding indigenous cultivars of tall plant type. This paper reports the effect of agronomic management on the yield and yield components of an indigenous rice cultivar, Sadamota. The trial was conducted in 10 farmers' plots located widely apart in two upazila (sub-districts) -Jhalakati and Rajapur. 45 d and $60 \mathrm{~d}$ old seedlings were transplanted either in rows at $40 \mathrm{~cm} \times 20 \mathrm{~cm}$ spacing or following farmers' traditional practice of random planting. Transplanting $60 \mathrm{~d}$ old seedlings produced $14 \%$ higher yield compared with $\mathbf{4 5} \mathrm{d}$ old seedlings. Transplanting in rows also increased grain yield by $12 \%$. The yield increase was associated with hill density, the number of effective tillers per hill and the number of spikelets per panicle.
\end{abstract}

\section{Keywords}

Rice, Seedling Age, Planting Method, Tidal Floodplain Tillers, Seedling Dry Weight, Grain Yield

\footnotetext{
${ }^{*}$ Corresponding author.
}

How to cite this paper: Hamid, A., Ullah, M.J., Haque, M.M., Mollah, M.F.H. and Rahman, M.M. (2015) Improving Grain Yield of IndigenousRice in Tidal Floodplain of SouthernBangladesh: Effect of Seedling Ageand Transplanting Method. Agricultural Sciences, 6, 1538-1546. http://dx.doi.org/10.4236/as.2015.612147 


\section{Introduction}

Rice is the major staple of over half of the world's population. It is the most important crop in the life and economy of Asian countries. In Bangladesh, nearly 80 per cent of crop land is planted to rice producing about 35 million tons of rice annually. It provides employment opportunity to nearly half of the country's total population. Bangladesh has had a rich treasure of indigenous rice cultivars and landraces. However, with the advent of high yielding, fertilizer responsive, short duration varieties of modern rice, farmers gradually abandoned cultivation of indigenous varieties. Most of the indigenous cultivars and landraces that endured generations and centuries are now extinct and those still survive remain threatened. Farmers grow traditional rice only in areas where agro-ecological conditions are not favorable for growing HYVs. These traditional cultivars are in fact landraces [1]. Most traditional aman rice cultivars are tall, long duration, and photoperiod-sensitive with low yield potential. Farmers in tidal floodplain of Jhalakati and adjoining areas of Pirojpur, Barguna and Patuakhali districts covering substantial area of Southern Delta Region [2] grow traditional aman rice cultivars. The region is at the proxymity of the sea and inland estuaries, and influenced by tides. Lands are subject to seasonal flooding and remain inundated July through October. High tide followed by low tide twice a day is the characteristics feature of the Gangetic Tidal Floodplain ecosystem. Tidal floodplain constitutes an important agro-ecological zone covering an extensive area in the south central coastal region of Bangladesh [3]. Brammer [4] provides general features of tidal floodplain. Crop production is seriously constrained with uncontrolled floodwater during the wet season. The high yielding modern rice varieties are dwarf and semi-dwarf and not suitable for growing in medium highland and medium lowland subject to inundation due to tidal flooding. Thus farmers in the region grow tall statured traditional cultivars. Farmers of non-saline tidal floodplain ecosystem cultivate five major indigenous cultivars-Sadamota, Lalmota, Moulata, Nakhuchimota and Dudhkalom in extensive areas of Jhalakati and adjoining districts during aman season [5]. In an earlier paper [6] we reported that indigenous varieties performed better than modern varieties in the tidal floodplain of Southern Delta region. Bangladesh is one of the most vulnerable countries to climate change and sea level rise is predicted to affect a substantial part of the country. Agricultural production in the Southern Delta is predicted to be greatly affected. In view of increasing impact of sea level rise due to climate change [4] [7] cultivation of indigenous rice varieties is likely to persist so long appropriate long-statured HYVs are developed and introduced.

Indigenous rice cultivars grown in the tidal floodplain are tall with low yield potential [8] [9]. Low yield of indigenous varieties might be associated with farmers' evolved production practices for growing indigenous varieties or genetic yield potentials or both. High yield potential of indigenous cultivars has also been reported [10] [11]. High yields in rice are associated with large numbers of spikelets per unit area [12] and the weight of individual filled-spikelets. The number of spikelets per unit area depends on the number of panicles and the spikelets per panicle. Apart from varietal characteristics, planting density has large bearing on the number of productive tillers developed per hill or unit area. The number of spikelets per panicle is a highly variable trait that differs due to agronomic management including planting density, planting methods, row- and plant spacing, seedling age, etc. Agronomic management seeking increased productivity of indigenous rice cultivars has not been reported.

Planting methods giving variable plant spacing has significant effects on grain yield, tillers per unit area, panicles per hill and total spikelets per unit area [13]. In rice growing areas including Bangladesh row configurations are commonly maintained in transplanted rice. In fertile soils, transplanting at wide rows can show marked effects on grain yield if there is sufficient weed control [14]-[16]. However, the effect of row configuration on high tillering crops like rice is more ambiguous [17] [18]. Row spacing did not significantly influence grain yield of rice although there was a strong tendency towards increased grain yield with $18 \mathrm{~cm}$ drill-row spacing [19]. Awan et al. [20] reported the highest grain yield (6.02 t/ha) in line transplanting and the lowest yield (3.3 t/ha) in the randomly transplanting field. Row spacing, however, depends largely on the plant type and soil fertility conditions. BRRI [21] recommends row spacing of $25 \mathrm{~cm} \times 15 \mathrm{~cm}$ for growing high yielding modern varieties of rice under irrigated lowland conditions. The spacing corresponds to a density of $26.67 \mathrm{hills} \cdot \mathrm{m}^{-2}$. In contrast, farmers in the southern districts grow traditional rice cultivars randomly transplanted maintaining about 4 - 5 hills $\cdot \mathrm{m}^{-2}$. Such sparse transplanting of seedling is being popularized in China. Xu et al. [22] reported a favorable response of hybrid rice to "super sparse transplanting" giving identical grain yield at a wide range of planting densities between 7.51 and 21.64 hills $\cdot \mathrm{m}^{-2}$ suggesting high plasticity of rice growth and yield formation to population density and planting configuration. Zaman et al. [23] compared yield performance of an indigen- 
ous cultivar Biroyen with two modern varieties, BINA dhan 7 and BRRI dhan 34 and observed the highest grain yield and biomass yield in indigenous cultivar transplanted at $50 \mathrm{~cm} \times 50 \mathrm{~cm}$ spacing. In contrast, Duy et al. [24] reported greater yield potential of conventional transplanting with higher population density compared to sparse planting.

The age of seedlings at transplanting is an important criterion in rice production as it primarily contributes to the number of tillers produced per hill [25]. While the use of over-aged seedlings retards the general performance of crop and reduces the yield of crop [26], transplanting younger seedlings results in increased tillering, panicles per hill, more spikelets per panicle and thus higher yields per unit area. Reports on the benefit of transplanting young seedlings abound. System Rice Intensification or SRI stands on two basic principles-transplanting 8 - $15 \mathrm{~d}$ old seedlings, at wider spacing. Use of younger seedlings helps better stand establishment reducing transplanting shockand promoting early tiller formation. Sparsely planted seedlings can harness soil and aerial environment better for nutrition, solar radiation and $\mathrm{CO}_{2}$. Conversely, transplanting at narrow spacing increases inter- and intra-plant competition reducing growth and yield. Transplanting young seedlings of below 10 days of age in SRI, which produce higher number of tillers than normal rice production systems, contributes to higher grain yields [27].

Stoop et al. [28] reported that rice seedlings transplanted before commencing the fourth phyllochron retained their higher tillering potential than that of seedlings of more than 14 days old. Makarim et al. [29] observed that 14-day old seedlings performing better than transplanting 21- to 23-day old seedlings. McHugh et al. [30] and Thiyagarajan et al. [31] observed highest yields with $8-15$ days old seedlings transplanted at $25 \mathrm{hills} \cdot \mathrm{m}^{-2}$ in Madagascar and with 10-day old seedlings in Sumatra. Krishna et al. [27] observed high grain yields of 3.25 $\mathrm{t} \cdot \mathrm{ha} \mathrm{H}^{-1}$ with 12-day old seedlings than 8-, 16- and 25-day old seedlings and the yield decline of seedlings of latter three ages was primarily attributed to the reduction in the number of tillers. Hu et al. [32] demonstrated seasonal variation in the optimal seedling age. Although there are many reports of the benefits of transplanting younger seedlings [33], few researchers have examined seedling characteristics required for growing rice in unfavorable environment determining the contribution of young and older seedlings to plant growth and yield formation. Because of unpredictable tidal flooding depth and the risk of submergence at early growth stages, transplanting of older seedlings is practiced in South- and Southeast Asian countries [25]. To withstand the high water level, seedlings must be tall and most of the leaves must be above the water level. To decrease the chance of crop loss or damage, farmers transplant old seedlings. Shamsuzzaman and Haque [5] observed most farmers in lowlands and medium highlands of Jhalakati district transplanting 60 - 90-d old seedlings of indigenous varieties of rice in aman season when tidal flood level remains high. This is done mainly because land topography and hydrological condition do not favor growing modern varieties. Seedlings of indigenous varieties grow faster and taller than modern varieties. Our earlier findings [34] indicated that depending on toposequence 45 - 60 day-old seedlings of indigenous varieties grow sufficiently taller to cope with depth of tidal flooding immediately after transplanting. Seedlings older than 33 days up to 55 days give better yield under late transplanting for long duration varieties [35].

Throughout Asian countries and elsewhere farmers follow rice seedling transplanting in rows. In the inundated ricelands in the tidal floodplain farmers follow random transplanting of aged seedlings. Whether growing traditional varieties of rice in rows in tidal wetland can increase yield requires to be tested. As younger seedlings cannot cope with tidal flooding, whether transplanting at wider spacing helps producing large number of tillers as found in tidal floodplain requires to be investigated. Available literatures on seedling age at transplanting invariably focus on rice growing on medium highland under irrigated conditions where seedlings after transplanting normally do not encounter submergence due to tidal- or flash floods. Performance of seedlings of variable ages transplanted in non-saline tidal floodplain has not been adequately studied.

In this paper we report the effect of transplanting $45 \mathrm{~d}$ and $60 \mathrm{~d}$ old seedlings either in rows at $40 \mathrm{~cm} \times 20 \mathrm{~cm}$ configuration or following farmers' traditional practice of random planting without maintaining rows on growth and yield of an indigenous rice cultivar Sadamota.

\section{Materials and Methods}

An on-farm trial was conducted in three villages covering two upazila (sub-district) in Jhalakati district of southern Bangladesh. Ten farmers of North Uttampur and Challish Kahnia of Rajapur upazila and Sachilapur of Jhalakati upazila were involved in carrying out the trial. The experiment site in North Uttampur is located at 
$22^{\circ} 36.163^{\prime} \mathrm{N}$ latitude and $90^{\circ} 9.899^{\prime} \mathrm{E}$ longitude, and in Sachilapur at $22^{\circ} 33.057^{\prime} \mathrm{N}$ latitude and $90^{\circ} 9.704^{\prime} \mathrm{E}$ longitude. On the east the river Bishkhali flows from north to south parallel to all the three villages. On the west the villages are bounded by a relatively small river Jangalia. Crop lands, mostly medium lowlands, in the area are typically connected with the rivers by canals. Plots are usually inundated to a varying degree during high tides twice daily in the rainy season. Mean annual rainfall was about $2700 \mathrm{~mm}$; over $77 \%$ of rainfall occurring during June through October. Mean temperatures during the growing season ranged between $18.3^{\circ} \mathrm{C}$ and $33.1^{\circ} \mathrm{C}$. Soils in the study areas are clayey and clay-loam with low N, very low $\mathrm{P}$, medium high $\mathrm{K}$, high $\mathrm{S}$, medium low $\mathrm{Zn}$ and very high contents of $\mathrm{Ca}, \mathrm{Mg}, \mathrm{Cu}$ and $\mathrm{Fe}$ [36].

Each participating farmer planted rice crop in a large plot. Plot size varied between 0.134 ha and 0.385 ha. Seedlings of two age groups - $45 \mathrm{~d}$ and $60 \mathrm{~d}$, and two planting methods-transplanting in rows, 7 seedlings per hill, at $40 \mathrm{~cm} \times 20 \mathrm{~cm}$ configuration, and farmers' practice of random planting using $9-11$ seedlings per hill formed the treatment variables. The $2 \times 2$ factorial experiment was set up in a randomized block design. The 10 farmers' plots accommodating the experiment constituted replications.

Seedlings of aman rice (cv. Sadamota) were raised in nursery beds. Variety Sadamota is an indigenous variety extensively grown in the Southern Delta region of Bangladesh. A common nursery bed was established for two villages in Rajapur upazila and one for Jhalakati upazila. Seeds were soaked for 24 hrs followed by incubation in dark room for about 48 hrs and pre-germinated seeds were sown in the seedbeds at two different dates 12 June and 27 June, 2012. No fertilizers were applied in the seedbeds. Seedlings of two batches were uprooted on 12 August 2012 and transplanted in the selected plots. Prior to transplanting, land was prepared by walking-type tractor and a moderate dose of fertilizers ( $40 \mathrm{~kg} \mathrm{~N}, 15 \mathrm{~kg} \mathrm{P}_{2} \mathrm{O}_{5}$, and $25 \mathrm{~kg} \mathrm{~K}_{2} \mathrm{O}$ per ha) was applied and incorporated into the soil at final plowing. Top dressing of $\mathrm{N}$ fertilizer at around panicle initiation stage could not be done due to continual submergence of land.

At the time of transplanting, three samples each of 100 seedlings were taken at random from each batch of seedlings. Sampling was done carefully uprooting the seedlings from the seedbed. Sampled seedlings were washed in clean water and sub-samples each of 10 seedlings were taken to measure the length of seedlings. Sample seedlings were oven dried at $70^{\circ} \mathrm{C}$ to a constant weight and dry weight recorded.

Transplanting in rows at $40 \mathrm{~cm} \times 20 \mathrm{~cm}$ configuration should have a density of 12.5 hills $\cdot$ per $\cdot \mathrm{m}^{2}$. We measured the hill density immediately after transplanting and observed that the density ranged between 8.4 and 10.3 with an average of 9.7 hills.per. $\mathrm{m}^{2}$. In the farmers' practice of random planting, the density ranged between 4.8 and 8.6 with an average of 7.1 hills.per $\mathrm{m}^{2}$. Such a large variation in hill density was not unexpected. In order to avoid lodging and reduce transplanting shock farmers transplanted during high tides and maintaining rows and hill density precisely in inundated field is difficult [3]. The crop was grown under wetland condition without irrigation. The land was sufficiently wet or inundated due to high rainfall coupled with tidal flooding. Pest incidence was minimal and no pesticide was applied. Weeding was not required as the plots were nearly weed-free.

Rice matured and harvested in early January 2013. At maturity the experimental crop was sampled from an area of $10 \mathrm{~m} \times 5 \mathrm{~m}$ from the center of each sub-plot, threshed, grain moisture content determined using a digital grain moisture meter and grain yield recorded adjusting at $14 \%$ moisture content. Five hills were sampled at random from each sub-plot avoiding the border effect. Shoot length, the number of tillers per hill, effective tillers, total number of spikelets per panicle, and number of filled spikelets per panicle were recorded. 1000 grain weight was recorded using samples from the filled grains. Data thus generated were analyzed statistically and means compared using DMRT.

\section{Results}

Seedlings of two age groups were sampled prior to transplanting. Data on the variation in seedling characteristics pertaining to shoot height and shoot dry weight are presented in Table 1. Seedling age had marked influence on shoot height and seedling dry weight. As expected, the shoot height and dry weight were higher in 60 day old seedlings than 45 day old seedlings, but the growth in height and dry weight was disproportionate with increasing age. In the older seedlings shoot dry weight increased by $90 \%$ in but the corresponding increase in seedling height was $26 \%$.

Data on morphological characters of rice sampled at maturity are presented in Table 2. Both seedling age at transplanting and method of transplanting exerted significant influence on the morphological characters of rice. The mean number of hills $\cdot$ per $\mathrm{m}^{2}$ recorded immediately after transplanting were 7.1 and 8.7 for farmers' practice 
Table 1. Variation in seedling characteristics due to difference in age.

\begin{tabular}{ccc}
\hline Seedling age at transplanting & Seedling height, $\mathrm{cm}$ & Seedling dry weight, $\mathrm{mg}^{\circ} \mathrm{seedling}^{-1}$ \\
\hline 45 day & $49.8 \mathrm{~B}$ & $404 \mathrm{~B}$ \\
60 day & $62.8 \mathrm{~A}$ & $768 \mathrm{~A}$ \\
\hline
\end{tabular}

Within a column, means followed by the same letters are not significantly different at $\mathrm{P} \leq 0.05$ by DMRT.

Table 2. Effect of seedling age and transplanting system on the growth and yield of rice.

\begin{tabular}{|c|c|c|c|c|c|c|c|}
\hline Treatment & Hills $\cdot \mathrm{m}^{-2}$ & Tillers·hill ${ }^{-1}$ & $\begin{array}{l}\text { Effective } \\
\text { tillers }^{-} \text {hill }^{-1}\end{array}$ & $\begin{array}{l}\text { Non-effective } \\
\text { tillers hill }^{-1}\end{array}$ & Tillers $\cdot \mathrm{m}^{-2}$ & $\begin{array}{l}\text { Effective } \\
\text { tillers } \mathrm{m}^{-2}\end{array}$ & $\begin{array}{c}\text { Plant height, } \\
\mathrm{cm}\end{array}$ \\
\hline \multicolumn{8}{|c|}{ Seedling age effect } \\
\hline $45 \mathrm{~d}$ seedlings & 6.1 & 25.1 & 21.3 & $3.8 \mathrm{~B}$ & 164.5 & 150.7 & 137.2 \\
\hline \multirow[t]{2}{*}{60 d seedlings } & 5.9 & 24.0 & 19.7 & $4.5 \mathrm{~A}$ & 168.4 & 154.2 & 138.5 \\
\hline & NS & NS & $*$ & $*$ & NS & NS & NS \\
\hline \multicolumn{8}{|c|}{ Planting system } \\
\hline $\mathrm{FP}(\approx 50.6 \mathrm{~cm})$ & $5.6 \mathrm{~B}$ & 24.3 & 20.5 & 3.9 & $161.8 \mathrm{~B}$ & $147.2 \mathrm{~B}$ & 136.1 \\
\hline \multirow[t]{2}{*}{ Row $(40 \mathrm{~cm} \times 20 \mathrm{~cm})$} & $6.4 \mathrm{~A}$ & 24.5 & 20.6 & 4.2 & $171.2 \mathrm{~A}$ & $157.7 \mathrm{~A}$ & 139.5 \\
\hline & $*$ & NS & NS & NS & * & $*$ & NS \\
\hline \multicolumn{8}{|c|}{ Seedling age $\times$ planting system } \\
\hline 45 d, FP & $6.1 \mathrm{~A}$ & $26.9 \mathrm{~A}$ & $23.2 \mathrm{~A}$ & 3.8 & 160.2 & $145.3 \mathrm{~B}$ & 134.4 \\
\hline 45 d, Row $(40 \mathrm{~cm} \times 20 \mathrm{~cm})$ & $6 \mathrm{~A}$ & $23.3 \mathrm{~B}$ & $19.5 \mathrm{AB}$ & 3.8 & 168.3 & $156 \mathrm{~A}$ & 139.9 \\
\hline 60 d, FP & $5 \mathrm{~B}$ & $21.6 \mathrm{~B}$ & $17.7 \mathrm{~B}$ & 3.9 & 162.8 & $149 \mathrm{~B}$ & 137.8 \\
\hline \multirow[t]{2}{*}{60 d, Row $(40 \mathrm{~cm} \times 20 \mathrm{~cm})$} & $6.7 \mathrm{~A}$ & $26.3 \mathrm{~A}$ & $21.7 \mathrm{~A}$ & 4.5 & 174 & $159.4 \mathrm{~A}$ & 139.1 \\
\hline & * & * & $*$ & NS & * & $*$ & NS \\
\hline
\end{tabular}

Within a column, means followed by the same letters are not significantly different at $\mathrm{P} \leq 0.05$ by DMRT; *Significance at the 0.05 level based on analysis of variance; and **Significance at the 0.01 level based on analysis of variance; NS denotes non-significant based on analysis of variance; FP-farmers' traditional practice of transplanting seedlings at random.

and row planting, respectively; but the number of hills at harvest ranged between 5.0 and 6.7 per $\cdot \mathrm{m}^{2}$ across the treatments. Reduction in the number of hills over the growing season could be attributed to the damage or plant mortality due to tidal flood. It was apparent that reduction in hills was more in farmers' practice (30\%) than in row planting (23\%). Seedling age exerted no significant influence on hill density (Table 2); but greater mortality of hills in farmers' plot accentuated the variation in hill density between farmers' practice and transplanting in row. Interaction effect between seedling age and planting method in respect of hill density was also significant but highly inconsistent.

Neither the seedling age nor the planting system created any significant difference in plant height (Table 2). Our results are in agreement with Amin and Haque [37] who observed no significant difference in plant height at 75 DAT onwards using seedlings of variable ages. Ali et al. [38], however, found the highest plant height transplanting $30 \mathrm{~d}$ old seedlings compared to younger seedlings.

The number of hills per unit area was more in row planting than in farmers' traditional random transplanting system (Table 2). Wider spacing in the traditional planting reduced the number of hills per unit area. Despite larger number of seedlings transplanted per hill, traditional transplanting system did not produce greater number of tillers per hill. Increased number of hills per unit area with identical number of tillers per hill resulted in significantly larger number of tillers per unit area in row planting system. Interaction effect of seedling age and planting system on the number of hills $\mathrm{m}^{-2}$, tillers per hill, and effective tillers per hill were statistically significant. Row planting with $60 \mathrm{~d}$ old seedlings at $40 \mathrm{~cm} \times 20 \mathrm{~cm}$ spacing resulted in higher number of hills per unit area and more tillers per hill which was closely followed by row planting with $45 \mathrm{~d}$ old seedlings. Aged seedling 
with higher dry matter content and greater assimilatory system might have contributed to producing larger number of tillers. Tiller production is an important trait for yield formation in rice. Large variation in tillering capacity among varieties has been reported [39]. Indigenous variety Sadamota produced large number of tillers per hill that varied between 21.6 and 26.9 across treatments. Altering tiller production due to variation in agronomic practices has been reported earlier [40]. Number of tillers per hill tended to be higher in row planting than in farmers' practice but the difference was not statistically different. Number of effective tillers per unit area was more in row planting compared with farmers' practice. Cumulative effect of greater number of hills per hill and slightly larger number of tillers per hill contributed to significantly greater number of tillers per unit area in row planting system.

There was significant effect of seedling age, planting method and interaction thereof on yield and yield components of rice (Table 3). Averaged over planting methods, transplanting $60 \mathrm{~d}$ old seedlings increased grain yield by nearly $14 \%$ compared with $45 \mathrm{~d}$ old seedlings. Likewise, transplanting in rows at $40 \mathrm{~cm} \times 20 \mathrm{~cm}$ spacing produced about $12 \%$ more grain yield than traditional planting. Interaction of seedling age and planting method increased grain yield ranging from $8 \%$ to $12 \%$. The highest grain yield was obtained with transplanting 60 days old seedlings in rows at $40 \mathrm{~cm} \times 20 \mathrm{~cm}$ spacing while the lowest yield with traditional transplanting of $45 \mathrm{~d}$ seedlings. Higher grain yield in row planting with $60 \mathrm{~d}$ old seedlings was associated with total spikelets per hill, spikelets per panicle and filled spikelets per panicle. Transplanting older seedlings increased spikelets per panicle by $12 \%$. Row planting also increased spikelets per panicle by $11 \%$.

There was a small but significant increase (3.38\%) in grain weight per hill by planting $60 \mathrm{~d}$ old seedlings compared with $45 \mathrm{~d}$ old seedlings. Row planting increased grain weight per hill by nearly $10 \%$ compared with traditional practice. Interaction effect of seedling age and planting method on grain yield per hill was statistically significant but not consistent. Our results compare favorably with that of Ginigaddara and Ranamukhaarachchi [41] who reported that plant height, total number of tillers $\cdot$ hill ${ }^{-1}$, number of effective tillers hill $^{-1}$, number of non-effective tillers·hill ${ }^{-1}$, length of panicle, 1000 grain weight and harvest index did not vary among different

Table 3. Seedling age and planting system effect on grain yield and yield attributes of rice.

\begin{tabular}{|c|c|c|c|c|c|c|c|c|}
\hline Treatments & $\begin{array}{l}\text { Spikelets } \\
\text { panicle }^{-1}\end{array}$ & $\begin{array}{l}\text { Filled spikelets } \\
\text { hill }^{-1}\end{array}$ & $\begin{array}{l}\text { Unfilled spikelets } \\
\text { hill }^{-1}\end{array}$ & $\begin{array}{l}\text { Total spikelets } \\
\text { hill }^{-1}\end{array}$ & $\begin{array}{c}\text { Grain } \\
\text { filling \% }\end{array}$ & $\begin{array}{c}\text { Grain } \\
\text { wt. hill }{ }^{-1} \text { (g) }\end{array}$ & $\begin{array}{l}\text { 1000-grain } \\
\text { wt. (g) }\end{array}$ & $\begin{array}{c}\text { Grain yield } \\
\left(\mathrm{t} \cdot \mathrm{ha}^{-1}\right)\end{array}$ \\
\hline \multicolumn{9}{|c|}{ Seedling age effect } \\
\hline $45 \mathrm{~d}$ seedlings & $67.7 \mathrm{~B}$ & 1375 B & $173 \mathrm{~A}$ & 1548 B & 88.8 & 44.955 & 30.155 & $3.093 \mathrm{~B}$ \\
\hline \multirow[t]{2}{*}{$60 \mathrm{~d}$ seedlings } & $84.2 \mathrm{~A}$ & $1457 \mathrm{~A}$ & $148 \mathrm{~B}$ & $1605 \mathrm{~B}$ & 90.8 & 46.1 & 31.175 & $3.519 \mathrm{~A}$ \\
\hline & $* *$ & $*$ & $*$ & $*$ & NS & NS & NS & * \\
\hline \multicolumn{9}{|c|}{ Planting system } \\
\hline $\mathrm{FP}(\approx 50.6 \mathrm{~cm})$ & $72.3 \mathrm{~B}$ & $1285 \mathrm{~B}$ & 165 & 1449 B & 88.6 & 88.647 & 30.44 & 3.065 B \\
\hline \multirow[t]{2}{*}{$\begin{array}{c}\text { Row } \\
(40 \mathrm{~cm} \times 20 \mathrm{~cm})\end{array}$} & $79.7 \mathrm{~A}$ & 1547 A & 156 & $1703 \mathrm{~A}$ & 90.8 & 90.837 & 30.89 & $3.447 \mathrm{~A}$ \\
\hline & $*$ & $* *$ & NS & $* *$ & NS & NS & NS & $*$ \\
\hline \multicolumn{9}{|c|}{ Seedling age $\times$ planting system } \\
\hline $45 \mathrm{~d}, \mathrm{FP}$ & 65.4 & $1467 \mathrm{AB}$ & $207 \mathrm{AB}$ & $1674 \mathrm{AB}$ & 87.6 & $48.81 \mathrm{~A}$ & 30.03 & $2.991 \mathrm{C}$ \\
\hline $\begin{array}{l}45 \mathrm{~d} \text {, Row planting } \\
(40 \times 20 \mathrm{~cm})\end{array}$ & 70.0 & 1242 B & $138 \mathrm{~B}$ & $1420 \mathrm{~B}$ & 90.3 & $41.1 \mathrm{~B}$ & 30.28 & 3.195 BC \\
\hline $60 \mathrm{~d}, \mathrm{FP}$ & 79.1 & 1102 B & $122 \mathrm{~B}$ & 1224 B & 90.0 & 36.2 B & 30.85 & 3.340 B \\
\hline \multirow[t]{2}{*}{$\begin{array}{l}60 \text { d, Row planting } \\
(40 \times 20 \mathrm{~cm})\end{array}$} & 89.3 & $1811 \mathrm{~A}$ & $174 \mathrm{~A}$ & 1985 A & 91.2 & $52.0 \mathrm{~A}$ & 31.50 & 3.698 A \\
\hline & $* *$ & $* *$ & $* *$ & $* *$ & NS & $*$ & NS & $*$ \\
\hline
\end{tabular}

Within a column, means followed by the same letters are not significantly different at $\mathrm{P} \leq 0.05$ by DMRT; *Significance at the 0.05 level based on analysis of variance; and **Significance at the 0.01 level based on analysis of variance; NS denotes non-significant based on analysis of variance; FP-farmers' traditional practice of transplanting seedlings at random. 
ages of seedlings. Highest grain weight per hill was recorded for $60 \mathrm{~d}$ old seedlings transplanted in rows followed by farmers' practice of transplanting $45 \mathrm{~d}$ old seedlings transplanted at random. The lowest yield was obtained for farmers' practice of random planting with $45 \mathrm{~d}$ old seedlings. From the results it is apparent that the difference in grain yield per ha was mainly associated with the number of hills per unit area and spikelets per panicle. Grain filling rate was fairly high that ranged between $87.6 \%$ and $91.2 \%$ across the treatments; the difference was not statically significant. Likewise, grain size or 1000-grain weight ranged between $30.03 \mathrm{~g}$ and $31.5 \mathrm{~g}$ across treatments; but the difference among the treatments was not significant.

\section{Discussion}

Higher yield in rice is associated with greater number of spikelets, higher seed setting rate and filling degree [42]. Lower yield potential of most indigenous rice cultivars and landraces might be due to lesser number of panicles per unit area, fewer spikelets per panicle, poor grain filling rate [13] [43]. Higher yield is often associated with high dry matter accumulation [32], but high translocation rate after heading directly contributes to grain formation that eventually results in higher yield in cereal crops. Dry matter production per hill or per unit area was fairly high in our study (data not shown) thus the poor yield cannot be attributed to lack of adequate dry matter production. Poor translocation and partitioning of assimilates into grains might have reduced the grain yield. Relatively lower yield and exceedingly low harvest index in indigenous cultivars indicate the potential constraint of translocation of biomass to grains during grain filling stage. Grain filling percentage was high and seedling age at transplanting was found to have no significant influence on it. In our study, low yield was also associated with a fewer number of spikelets per panicle suggesting that major constraining factor in grain yield was the poor sink capacity.

Seedling age induced variation in grain yield and associated traits are also related to cultivars [44]. The cultivar that we used in our study had high tillering potential and wide spacing maintained both in row planting and farmers' practice provided enough room for developing tillers and thus despite super sparsely planting [22], the number of tillers and panicles at harvest was comparable to the optimal densities suggested for HYVs [13]. But the number of spikelets per panicle was much less compared to hybrids or HYVs. The number of spikelets per panicle is highly variable character [45] and largely influenced by environmental and management factors [46]. Any attempt to improving yield of indigenous rice will require increasing spikelets per panicle.

\section{Conclusion}

Transplanting 60 days old seedlings in rows at $40 \mathrm{~cm} \times 20 \mathrm{~cm}$ spacing gave yield advantage of $12 \%$ - 14\% in traditional rice cultivar Sadamota. In the tidal floodplain of south central coastal region of Bangladesh where high yielding varieties are not suitable for cultivation, the traditional cultivars of aman rice will continue to dominate. Adopting the improved agronomic practices for indigenous rice varieties may substantially increase yield and profit.

\section{Acknowledgements}

This work was funded by the Krishi Gobeshona Foundation, Dhaka through a CGP project C-2.20.

\section{References}

[1] Zeven, A.C. (1998) Landraces: A Review of Definition and Classification. Euphytica, 104, 127-139. http://dx.doi.org/10.1023/A:1018683119237

[2] Food and Agriculture Organization (FAO) (2014) Master Plan for Agricultural Development in the Southern Region of Bangladesh. Food and Agriculture Organization of the United Nations, Dhaka, 104 p.

[3] Roy, B.C., Hossain, M.A. and Khan, M.A.I. (2003) Suitable Transplanting Time for the Modern T. Aman Rice Varieties in Tidal Non-Saline Wetland Situation of Bangladesh. Pakistan Journal of Biological Sciences, 6, 661-665. http://dx.doi.org/10.3923/pjbs.2003.661.665

[4] Brammer, H. (2014) Bangladesh’s Dynamic Coastal Regions and Sea-Level Rise. Climate Risk Management, 1, 51-62. http://dx.doi.org/10.1016/j.crm.2013.10.001

[5] Shamsuzzaman, K.M. and Haque, M.M. (2010) Performance of Modern Varieties of Transplanted Aman Rice and Mungbean in Selected Locations in Tidal Floodplain. In: Jafarullah, M., Ed., Crop Production in the Coastal Ecosystem-Challenges and Opportunities, Agrarian Research Foundation, Dhaka, 26-30. 
[6] Hamid, A., Ullah, M.J., Mollah, M.F.H. and Akbar, M.A. (2015) Traditional Rice Varieties Perform Better in Tidal Floodplain. International Journal of Advanced Research, 3, 1316-1321.

[7] Dasgupta, P., Morton, J.F., Dodman, D., Karapınar, B., Meza, F., Rivera-Ferre, M.G., ToureSarr, A. and Vincent, K.E. (2014) Rural Areas. In: Field, C.B., Barros, V.R., Dokken, D.J., Mach, K.J., Mastrandrea, M.D., Bilir, T.E., Chatterjee, M., Ebi, K.L., Estrada, Y.O., Genova, R.C., Girma, B., Kissel, E.S., Levy, A.N., MacCracken, S., Mastrandrea, P.R., and White, L.L., Eds., Climate Change 2014: Impacts, Adaptation, and Vulnerability. Part A: Global and Sectoral Aspects. Contribution of Working Group II to the Fifth Assessment Report of the Intergovernmental Panel on Climate Change, Cambridge University Press, Cambridge, UK and New York, NY, USA, 613-657.

[8] Amin, M.R., Hamid, A., Choudhury, R.U., Raquibullah, S.M. and Asaduzzaman, M. (2006) Nitrogen Fertilizer Effect on Tillering, Dry Matter Production and Yield of Traditional Varieties of Rice. International Journal of Sustainable Crop Production, 1, 17-20.

[9] Islam, M.S., Peng, S.B., Visperas, R.M., Bhuiya, M.S.U., Hossain, S.A. and Julfiquar, A.W. (2010) Comparative Study on Yield and Yield Attributes of Hybrid, Inbred, and NPT Rice Genotypes in a Tropical Irrigated Ecosystem. Bangladesh Journal of Agricultural Research, 35, 343-353. http://dx.doi.org/10.3329/bjar.v35i2.5897

[10] Dey, D. (2014) Agro Ecological Landscapes: Conserving Indigenous Rice in Coastal Sundarbans. LEISA India, 16, 1517.

[11] Sinha, A.K. and Mishra, P.K. (2015) Are the Traditional Rice Varieties Low Yielding? A Case Study on Traditional Rice Varieties of Lateritic Region of West Bengal. International Journal of Advanced Research, 3, 292-296.

[12] De Datta, S.K. (1981) Principle and Practices of Rice Production. John Wiley and Sons, New York.

[13] Yang, Z.Y., Li, N., Ma, J., Sun, Y.Z. and Xu, H. (2014) High-Yielding Traits of Heavy Panicle Varieties under Triangle Planting Geometry: A New Plant Spatial Configuration for Hybrid Rice in China. Field Crops Research, 168, 135-147. http://dx.doi.org/10.1016/j.fcr.2014.07.017

[14] Janovicek, K.J., Deen, W. and Vyn, T.J. (2006) Soybean Response to Zone Tillage, Twin-Row Planting, and Row Spacing. Agronomy Journal, 98, 800-807. http://dx.doi.org/10.2134/agronj2005.0231

[15] Whish, J., Butler, G., Castor, M., Cawthray, S., Broad, I., Carberry, P., Hammer, G.L., Mclean, G., Routley, R. and Yeates, S. (2005) Modelling the Effects of Row Configuration on Sorghum Yield Reliability in North-Eastern Australia. Australian Journal of Agricultural Research, 56, 11-23. http://dx.doi.org/10.1071/AR04128

[16] Mahajan, G. and Chauhan, B.S. (2011) Effects of Planting Pattern and Cultivar on Weed and Crop Growth in Aerobic Rice System. Weed Technology, 25, 521-525. http://dx.doi.org/10.1614/WT-D-11-00025.1

[17] Chauhan, B.S. and Johnson, D.E. (2010) Implications of Narrow Crop Row Spacing and Delayed Echinochloa colona and Echinochloa crusgalli Emergence for Weed Growth and Crop Yield Loss in Aerobic Rice. Field Crops Research, 117, 177-182. http://dx.doi.org/10.1016/j.fcr.2010.02.014

[18] Lampayan, R.M., Bouman, B.A.M., de Dios, J.L., Espiritu, A.J., Soriana, J.B., Lactaoen, A.T., Faronilo, J.E. and Thant, K.M. (2010) Yield of Aerobic Rice in Rainfed Lowlands of the Philippines as Affected by Nitrogen Management and Row Spacing. Field Crops Research, 116, 165-174. http://dx.doi.org/10.1016/j.fcr.2009.12.007

[19] Frizzell, D.L., Wilson Jr., E.E., Norman, R.J., Slaton, N.A., Richards, A.L. and Runsick, S.K. (2007) Influence of Row Spacing and Seeding Rate on Grain Yield of Hybrid Rice. In: Norman, R.J., Mullenet, J.F. and Moldenhauer, K.A.K., Eds., B.R. Wells. Rice Research Studies 2006, Research Series 541, Arkansas Agricultural Experiment Station, University of Arkansas, Fayetteville, 294-297.

[20] Awan, T.H., Ahmad, M., Ashraf, M.M. and Ali, I. (2011) Effect of Different Transplanting Methods on Paddy Yield and Its Components at Farmer's Field in Rice Zone of Punjab. Journal of Animal and Plant Sciences, 21, 498-502.

[21] Bangladesh Rice Research Institute (BRRI) (2010) Cultivation of Modern Rice. Joydebpur, Gazipur, 47 p.

[22] Xu, F., Zheng, J., Zhu, Y., Wang, G., Yang, D. and Liu, K. (2004) Effect of Super Sparse Cultivation on Head Milled Rice Percentage and Chalkiness in Hybrid Rice Varieties in the Eastern and Southern Districts of Sichuan Province. Chinese Journal of Plant Ecology, 28, 686-691. (In Chinese) http://dx.doi.org/10.17521/cjpe.2004.0092

[23] Zaman, H., Masum, S.M., Ali, M.H., Biswas, P.K., Mandal, M.S.H. and Mehraj, H. (2015) Tiller Production and Yield Improvement of T. Aman Rice Varieties through Wider Spacing. Middle-East Journal of Scientific Research, 23, 1114-1121.

[24] Duy, P.Q., Hirano, M., Sagawa, S. and Kuroda, E. (2004) Varietal Differences in Tillering and Yield Responses of Rice Plants to Nitrogen-Free Basal Dressing Accompanied with Sparse Planting Density in the Tohoku Region of Japan. Plant Production Science, 7, 3-10. http://dx.doi.org/10.1626/pps.7.3

[25] Bhattacharya, S.N. and Vergara, B.S. (1979) Importance of Seedling Age in Transplanted Rice. Proceedings of International Deepwater Rice Workshop, International Rice Research Institute, Los Banos, 173-183.

[26] Bozorgi, H.R., Faraji, A., Danesh, R.K., Keshavarz, A., Azarpour, E. and Tarighi, F. (2011) Effect of Plant Density on Yield and Yield Components of Rice. World Applied Sciences Journal, 12, 2053-2057. 
[27] Krishna, A., Biradarpatil, N.K. and Channappagoudar, B.B. (2008) Influence of System of Rice Intensification (SRI) Cultivation on Seed Yield and Quality. Karnataka Journal of Agricultural Sciences, 21, 369-372.

[28] Stoop, W.A., Uphoff, N. and Kassam, A. (2002) A Review of Agricultural Research Issues Raised by the System of Rice Intensification (SRI) from Madagascar: Opportunities for Improving Farming Systems for Resource-Poor Farmers. Agricultural Systems, 71, 249-274. http://dx.doi.org/10.1016/S0308-521X(01)00070-1

[29] Makarim, A.K., Balasubramanian, V., Zaini, Z., Syamsiah, I., Diratmadja, I.G.P.A. and Handoko, A. (2002) Systems of Rice Intensification (SRI): Evaluation of Seedling Age and Selected Components in Indonesia. In: Bouman, B.A.M., Hengsdijk, A., Hardy, B., Bindraban, P.S., Tuong, T.P. and Ladha, J.K., Eds., Water-Wise Rice Production, IRRI, Los Baños, 129-139.

[30] McHugh, O.V., Steenhuis, T.S., Barison, J., Fernandes, E. C. M. and Uphoff, N.T. (2002) Farmer Implementation of Alternate Wet-Dry and Nonflooded Irrigation Practices in the System of Rice Intensification (SRI). In: Bouman, B.A.M., Hengsdijk, A., Hardy, B., Bindraban, P.S., Tuong, T.P. and Ladha, J.K., Eds., Water-Wise Rice Production, IRRI, Los Baños, 89-103.

[31] Thiyagarajan, T.M., Velu, V., Ramasamy, S., Durgadevi, D., Govindaranjan, K. and Pryadarshini, R. (2002) Effects of SRI Practices on Hybrid Rice Performance in Tamil Nadu, India. In: Bouman, B.A.M., Hengsdijk, A., Hardy, B., Bindraban, P.S., Tuong, T.P. and Ladha, J.K., Eds., Water-Wise Rice Production, IRRI, Los Baños, 119-129.

[32] Hu, Z., Liu, Y., Huang, L., Peng, S., Nie, L., Cui, K., Huang, J. and Wang, F. (2015) Premature Heading and Yield Losses Caused by Prolonged Seedling Age in Double Cropping Rice. Field Crops Research, 183, 147-155. http://dx.doi.org/10.1016/j.fcr.2015.08.002

[33] Horie, T., Lubis, I., Takai, T., Ohsumi, A. and Kuwasaki, K. (2003) Physiological Traits Associated with High Yield Potential in Rice. In: Mew, T.W., Brar, D.S., Peng, S., Dawe, D. and Hardy, B., Eds., Rice Science: Innovations and Impact for Livelihood. Proceedings of the International Rice Research Conference, International Rice Research Institute, Beijing, 117-145.

[34] Hamid, A., Ullah, M.J, Haque, M.M., Rahman, M.M., Mollah, M.F.H. and Molla, M.R.I. (2015) Agronomic Management for Improving Rice Yield in Tidal Floodplain: Optimizing Seedling Age and Transplanting Date. Submitted to Agronomy.

[35] Anonymous (2013) Transplanting. Rice Knowledge Management Portal. www.rkmp.in/content/transplanting-6

[36] Soil Resource Development Institute (SRDI) (2008) Manual on the Use of Soil Resources. Jhalakati Sadar Upazila, Government of People's Republic of Bangladesh, 119 p.

[37] Amin, A.K.M.K. and Haque, M.A. (2009) Seedling Age Influence Rice (Oryza sativa L.) Performance. Philippine Journal of Science, 138, 219-226.

[38] Ali, M.S., Hasan, M.A., Sikder, S., Islam, M.R. and Hafiz, M.H.R. (2013) Effect of Seedling Age and Water Management on the Performance of Boro Rice (Oryza sativa L.) Variety BRRI Dhan28. The Agriculturists, 11, 28-37. http://dx.doi.org/10.3329/agric.v11i2.17484

[39] Nuruzzaman, M., Yamamoto, Y., Nitta, Y., Yoshida, T. and Miyazaki, A. (2000) Varietal Differences in Tillering Ability of Fourteen Japonica and Indica Rice Varieties. Soil Science and Plant Nutrition, 46, 381-391.

[40] Huang, M., Zou, Y., Jiang, P., Xia, B., Feng, Y., Cheng, Z. and Mo, Y. (2011) Yield Component Differences between Direct-Seeded and Transplanted Super Hybrid Rice. Plant Production Science, 14, 331-338. http://dx.doi.org/10.1626/pps.14.331

[41] Ginigaddara, G.A.S. and Ranamukhaarachchi, S.L. (2011) Study of Age of Seedlings at Transplanting on Growth Dynamics and Yield of Rice under Alternating Flooding and Suspension of Irrigation of Water Management. Recent Research in Science and Technology, 3, 76-88.

[42] Zhao, B.H., Wang, P., Zhang, H.X., Zhu, Q.S. and Yang, J.C. (2006) Source-Sink and Grain Filling Characteristics of Two-Line Hybrid Rice Yangliangyou 6. Rice Science, 13, 34-42.

[43] Liang, J., Cao, X. and Zhu, Q. (1994) The Changes of Stem-Sheath Reserve Contents of Rice and Affecting Factors during Grain Filling. Chinese Journal of Rice Science, 8, 151-156.

[44] Karmakar, J., Roychowdhury, R., Kar, R.K., Deb, D. and Dey, N. (2012) Profiling of Selected Indigenous Rice (Oryza sativa L.) Landraces of Rarh Bengal in Relation to Osmotic Stress Tolerance. Physiology and Molecular Biology of Plants, 18, 125-132. http://dx.doi.org/10.1007/s12298-012-0110-1

[45] Deshmukh, D., Singh, A., Jain, N., Anand, S., Gacche, R., Singh, A., Gaikwad, K., Sharma, T., Mohapatra, T. and Singh, N. (2010) Identification of Candidate Genes for Grain Number in Rice (Oryza Sativa L.). Functional \& Integrative Genomics, 10, 339-347. http://dx.doi.org/10.1007/s10142-010-0167-2

[46] Kovi, M.R., Bai, X., Mao, D. and Xin, Y. (2011) Impact of Seasonal Changes on Spikelets per Panicle, Panicle Length and Plant Height in Rice (Oryza sativa L.). Euphytica, 179, 319-331. http://dx.doi.org/10.1007/s10681-010-0332-7 